\title{
Failings exposed at India's drug regulator
}

\section{Inadequate testing and insufficient staffing plague the granting of pharmace utical licences.}

\section{Gayathri Vaidyanathan}

18 May 2012

India's drug-regulatory system is failing in its job, according to a report from an Indian parliamentary committee. The report found evidence that pharmaceutical companies exploit loopholes in Indian law and sometimes collude with the drug-regulatory authority to get licences for their products without adequate tests being done.

The performance of the Central Drugs Standard Control Organization (CDSCO), based in New Delhi, was scrutinized by the Committee on Health and Family Welfare for a report presented in parliament earlier this month. Despite the CDSCO being India's equivalent of the US Food and Drug Administration, the committee's report revealed that it is understaffed and has insufficient resources to carry out its duties.

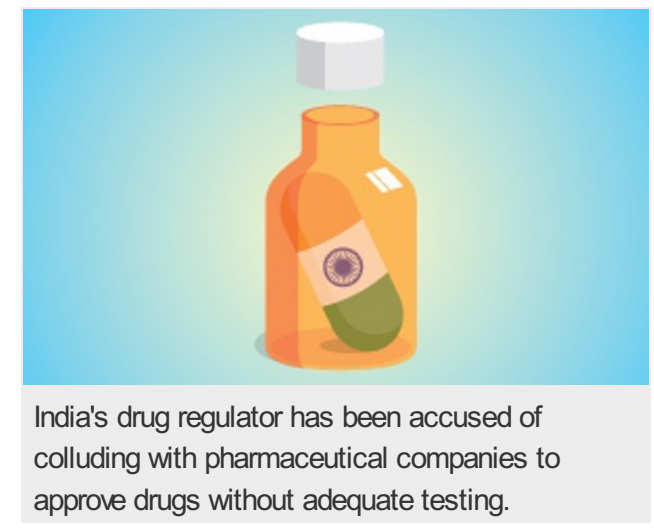

The report also highlights an apparent conflict of interest, which it suggests is at the heart of many of the CDSCO's problems: the agency's mandate is to "meet the aspirations ... demands and requirements of the pharmaceutical industry". The report suggests that this has led to "skewed priorities and perceptions" at the agency.

As part of its analysis, the parliamentary committee reviewed the approval process for 42 randomly selected drugs, most of which were awarded licences between 2004 and 2010. Documentation for three of the drugs - which the report describes as "controversial" because they are not licensed for use in most Western nations - was missing, and 11 of the remaining 39 had been licensed apparently without undergoing phase III clinical trials.

Drugs approved for use in other countries still have to undergo a phase III trial in India before they are approved because a patient's response to the treatment can be affected by their ethnic background. For example, the cholesterol-lowering drug rosuvastatin is effective in Asian patients at half the dose needed in Western patients ${ }^{1}$. The only time this requirement can be waived is in an emergency — such as the public health threat posed by H5N1 avian influenza. But the report found that such emergency exceptions have been granted by the CDSCO for an average of one drug every month between 2008 and 2010.

\section{Expert opinion}

The committee's report also raises concerns about the way in which licences were approved for the drugs it reviewed that bypassed clinical trials. The CDSCO sometimes granted exemptions without consulting experts, and at other times, the agency asked pharmaceutical companies to submit letters from doctors who vouched for the drugs. In some cases, the companies were allowed to choose these experts, who then provided letters that appeared to be word-for-word copies of each other.

"There is a nexus between the drug companies and the so-called experts, and the Drug Controller General of India," says Chandra Gulhati, editor of drug-reference guide the Monthly Index of Medical Specialities India. "If the opinion of three experts is sought, then you'd expect at least the language of the three letters to be different from each other."

Gyanendra Nath Singh, the Drug Controller General of India, who heads the CDSCO, did not respond to Nature's request for comment.

Blood-pressure drug ambrisentan, made by GlaxoSmithKline, was one of those approved by the CDSCO without clinical trials. The report does not mention whether the agency sought expert opinion on the drug before granting an exemption. The company notes that the drug has been approved in 44 countries and that those approvals were based on phase III trials in 400 patients of multiple ethnicities.

Two of the drugs approved without trials were made by Novartis, though the company was not one of those that submitted suspicious expert opinion letters. It says that its regulatory approvals are transparent, and were granted under rules that "allow concessions for 
drugs that treat a rare disease which is life threatening and debilitating".

Indian drug company Cipla also had two drugs that were approved without trials or expert opinion. The company denies any collusion with the CDSCO, saying that phase III trials are not mandatory for some drugs.

The committee was also scathing about the CDSCO's approval of 13 of the 42 drugs reviewed that are not licensed for use in most developed countries. The majority of these treatments were domestically manufactured tablets containing a mixture of two or more compounds, called fixed dose combinations (FDCs). These are supposed to make patients more likely to take their medication by reducing the complexity of their treatment.

But FDCs can cause problems: some that mix antibiotics can lead to the evolution of bacterial resistance, notes Gulhati. "If these combinations are valid and wonderful, why would Western countries not adopt them?" he asks.

Nature | doi:10.1038/nature.2012.10668

\section{References}

1. Yang, J. et al. Acta Pharmacol. Sinica. 32, 116-125 (2011). 